\title{
IDENTIFICATION OF ALTERNATIVE METHOD OF TEACHING AND LEARNING THE CONCEPT OF DIFFUSION TO SENIOR SECONDARY CHEMISTRY STUDENTS
}

BEATRICE ARISA AROP, U. D. AKPABIO AND JAMES O. IBE

(Received 5 June 2010; Revision Accepted 9, June 2010)

\begin{abstract}
This study examines alternative method of teaching and learning of the concept of diffusion. An improvised U-shape glass tube called ionic mobility tube was used to observed and measure the rate of movement of divalent metal ions in an aqueous medium in the absence of an electric current. The study revealed that the movement of ions can be effectively measured using ionic mobility tube, and this can be used to effectively teach the concept of diffusion. This study also showed that difficult and abstract concepts in chemistry can be effectively taught using improved instructional materials/apparatus. The study recommended the use of ionic mobility tube for the teaching and learning of the concept of diffusion in senior secondary chemistry curriculum.

\section{INTRODUCTION}

Diffusion refers to the process by which molecules spread from areas of high concentration to areas of low concentration. It is the inevitable scattering of particles resulting from natural random movement.

The concept of diffusion as put forward by Graham (1982) involves principally movement of particles in both liquid and gaseous phases and to some extent, the solid phase.

Therefore diffusion occurs in gases, liquids and solids. Two miscible liquids, for instance diffuse throughout the whole mixture until it is homogenous. A solution will diffuse into another solution, or into pure solvent, so long as the pairs of substances used are miscible (Brown, 1973). Brown (1973) further stated that it is possible, with care, to pour a saturated aqueous solution of Cupper (II) tetraoxosulphate (VI) through a tube into a vessel containing water so that the blue saturated solution, with higher density than water, forms a well defined lower layer. He indicated that on standing, the two layers slowly merge, until a homogenous mixture of uniform concentration is obtained. Water diffuses into copper (II) tetraoxoslphate (VI)

solution $\left(\mathrm{CuSO}_{4}\right)$ and $\mathrm{CuSO}_{4}$ diffuses into the water layer. The rate of diffusion is measured as the mass of solute passing per unit time from solution to solvent and increases rapidly with rise of temperature and is directly proportional to the concentration of the solution used. Diffusion also takes place if two solutions of unequal concentration are in contact. The solvent observed will pass from the dilute to the concentrated solution, until equality of concentration is achieved.

Eshiet (1988) observed that it is possible to compare by simple experimental measurements, the relative speeds (diffusion) of different ions in solution.

The kinetic theory postulated that matter is made up of very tiny particles such as atoms, molecules and ions, these particles are continually moving and so possess kinetic energy. However, when subjected to an increase temperature, it causes an increase in the average kinetic energy because in any given sample of a substance, some particles are more energetic, that is they move faster than others. The movement is however directional. The speed of an ion is related to its mobility by the equation.
\end{abstract}

Beatrice Arisa Arop, Department of Integrated Science Cross River State College of Education Akamkpa, Nigeria

U. D. Akpabio, Department of Chemistry University of Uyo Akwa Ibom State, Nigeria James O. Ibe, Department of Curriculum \& Instructional Technology Cross River University of Technology Calabar, Nigeria 
$\mathrm{V}=\mathrm{EU}$.

Where $V=$ speed of the ion

$$
\begin{aligned}
& E=\text { Electric field } \\
& U=\text { Mobility }
\end{aligned}
$$

Eshiet (1988) further noted that in the absence of external field, ion still move directionally provided there is a difference in chemical potential or concentration between parts of the system. This migration as a result of the difference in chemical potential is diffusion.

\section{Statement of the Problem}

Diffusion is an unobservable and abstract concept in chemistry. Because of this, teachers find it difficult to teach while students perceive the concept as abstract and too difficult to comprehend. It therefore becomes imperative to find alternative methods of teaching that would make this unobservable and abstract concept simple to teach and easy to learn. The problem is that chemists as well as teachers of chemistry do not have specific method and materials to teach the concept of diffusion in schools in order to make it simple and observable.

\section{Purpose of the Study}

The purpose of this study is to identify alternative methods of teaching the concept of diffusion in schools.

\section{Research Question}

To what extent does the use of ionic mobility tube influence the performance of students on the concept of diffusion?

\section{Method and Materials}

An improvised apparatus adopted from Eshiet (1988) was used to teach the concept of diffusion. The apparatus is called a U-shaped Ionic Mobility Tube (IMT) constructed from glass. The instrument is a $50 \mathrm{~cm}$ long U-shaped tube of about 1 inch thick with 2 side arms of about $20 \mathrm{~cm}$. Attach to each arm is a small tap to control the flow of the solvent. Air Pressure controls are attached below the taps $2 \mathrm{~cm}$ away from the taps.

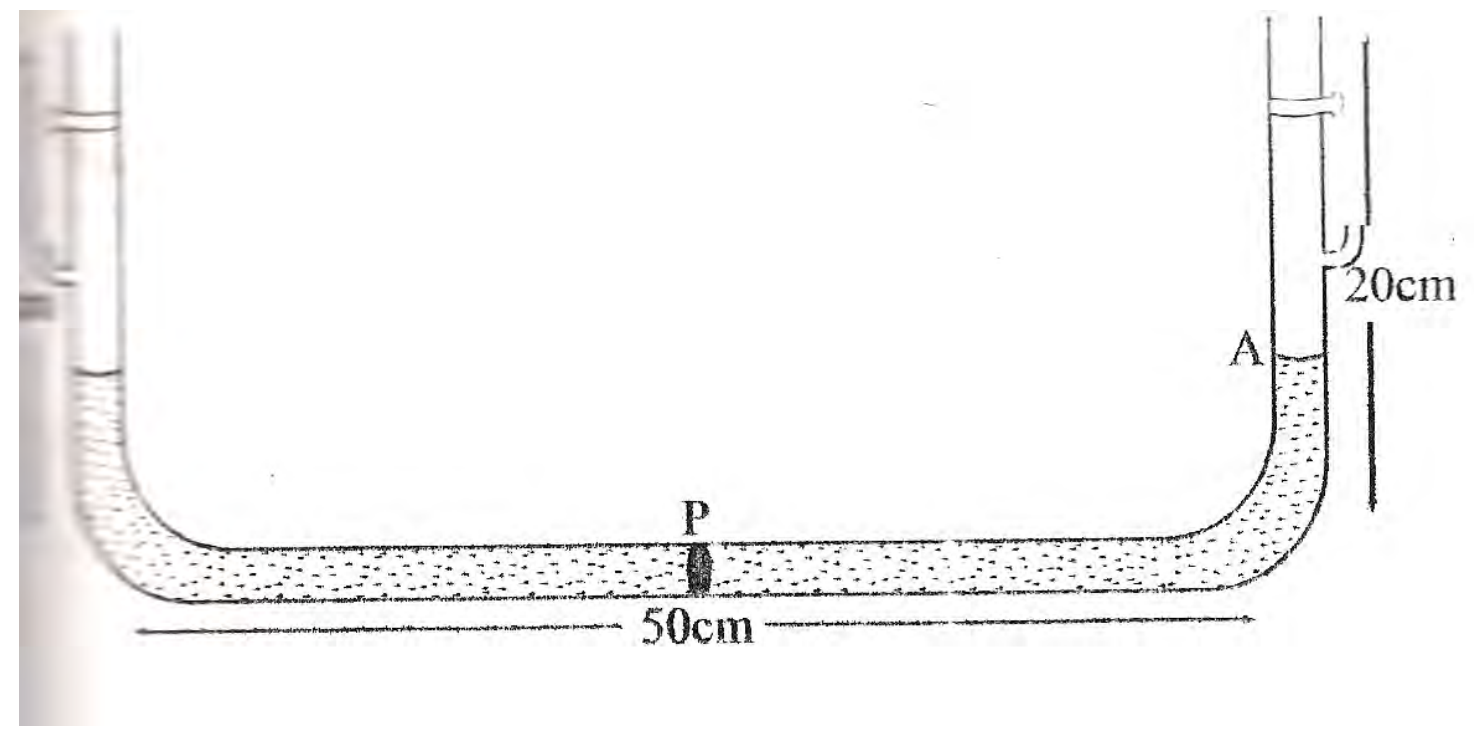

Fig. $1 U$-shaped Ionic Mobility Tube

Retord stand, $250 \mathrm{~cm}^{3}$ volumetric flask, weighing balance, metre rule, stop watch, thread and razor, distill water, salts of $\mathrm{Na}_{2} \mathrm{CO}_{3}, \mathrm{Ba}\left(\mathrm{NO}_{3}\right)_{2}, \mathrm{CaCl}_{2}, \mathrm{~Pb}\left(\mathrm{NO}_{3}\right), \mathrm{FeSO}_{4}$.

\section{Laboratory Procedure}

Weigh each divalent metal salt on a weighing balance to $0.01 \mathrm{~g}$ accuracy. $6.54 \mathrm{~g}$ of $\mathrm{Ba}\left(\mathrm{NO}_{3}\right)_{2}, 2.77 \mathrm{~g}$ of $\mathrm{CaCl}_{2}, 8.28 \mathrm{~g}$ of $\mathrm{Pb}\left(\mathrm{NO}_{3}\right)_{2}$, $3.89 \mathrm{~g}$ of $\mathrm{FeSO}_{4}$.

These were first dissolved in a small quantity of water, shaken to dissolve the salt and made up to $250 \mathrm{~cm}^{3}$. This forms a 0.1 molar solution. $26.5 \mathrm{~g} \mathrm{Na}_{2} \mathrm{CO}_{3}$ was equally dissolved in the same way and made up to $250 \mathrm{~m}^{3}$. This forms a 1 molar solution $\mathrm{Na}_{2} \mathrm{CO}_{3} . \mathrm{Na}_{2} \mathrm{CO}_{3}$ solution was used to precipitate the divalent metals in aqueous solution.

The ionic mobility glass tube was rinsed with distilled water then clamped horizontally and securely by both arms to two retort stands and 
then filled with distilled water at room temperature to a level $12 \mathrm{~cm}$ in each arm with the left and right taps closed. By using two dropping pipettes, $5 \mathrm{ml}$ of $0.1 \mathrm{M}$ solution of $\mathrm{Na}_{2} \mathrm{CO}_{3}$ was pipette into the left arm. The two taps were then simultaneously opened while a stop watch was started. The watch was stopped as soon as a ring precipitate $(P)$ started forming.
The distance 'AP' that the divalent metal had travelled was measured and the time taken was recorded in seconds. The experiment was repeated three times for each divalent metal ion. The average for both distance $(\mathrm{cm})$ and time (seconds) was calculated. The speed (diffusion) of the ion was determined by dividing distance in $\mathrm{cm}$ by time in seconds.

Results

Table 1: Diffusion of divalent metal ions in aqueous solution using $\mathrm{Na}_{2} \mathrm{CO}_{3}$ as precipitate (Researchers' Results)

\begin{tabular}{llllll}
\hline \hline $\begin{array}{l}\text { Divalent } \\
\text { Metal lons }\end{array}$ & $\begin{array}{l}\text { Distance } \\
\text { AP(cm) }\end{array}$ & $\begin{array}{l}\text { Average } \\
\text { Distance } \\
(\mathbf{c m})\end{array}$ & $\begin{array}{l}\text { Time } \\
(\mathbf{s e c})\end{array}$ & $\begin{array}{l}\text { Average } \\
\text { Time } \\
(\mathbf{s e c})\end{array}$ & $\begin{array}{l}\text { Speed/ } \\
\text { Diffusion } \\
\mathbf{c m ~ s e c}^{-1}\end{array}$ \\
\hline $\mathbf{P b}^{2+}$ & & & & 0.2949 \\
$1^{\text {st }}$ & 28.00 & & 96 & & \\
$2^{\text {nd }}$ & 27.50 & 27.60 & 95 & 93.67 & \\
$3^{\text {rd }}$ & 27.40 & & 90 & & \\
$\mathbf{B a}^{2+}$ & 30.00 & & 128 & & \\
$1^{\text {st }}$ & 29.50 & 29.47 & 124 & 126.00 & 0.2338 \\
$2^{\text {nd }}$ & 28.90 & & 126 & & \\
$3^{\text {rd }}$ & & & & & \\
$\mathbf{F e}^{2+}$ & 28.50 & & 139 & & \\
$1^{\text {st }}$ & 29.00 & 28.63 & 141 & 139.33 & 0.2055 \\
$2^{\text {nd }}$ & 28.40 & & 138 & & \\
$3^{\text {rd }}$ & & & & & \\
$\mathbf{C a}^{2+}$ & 22.10 & & 143 & & \\
$1^{\text {st }}$ & 22.50 & 22.27 & 140 & 139.67 & 0.1594 \\
$2^{\text {nd }}$ & 22.20 & & 139 & & \\
$3^{\text {rd }}$ & & & & & \\
\hline \hline
\end{tabular}

Table 1 above shows the diffusion rate of divalent metal ions in aqueous solution using $\mathrm{Na}_{2} \mathrm{CO}_{3}$ as precipitate as obtained by the reserved. The result indicates that the speed (sec) or diffusion rate of divalent metal ions is in the order $\mathrm{Pb}^{2+}>\mathrm{Ba}^{2+}>\mathrm{Fe}^{2+}>\mathrm{Ca}^{2+}$.

Table 2: Diffusion of divalent metal ions in aqueous solution using $\mathrm{Na}_{2} \mathrm{CO}_{3}$ as precipitate (students' results)

\begin{tabular}{llllll}
\hline \hline $\begin{array}{l}\text { Divalent } \\
\text { Metal lons }\end{array}$ & $\begin{array}{l}\text { Distance } \\
\mathbf{A P}(\mathbf{c m})\end{array}$ & $\begin{array}{l}\text { Average } \\
\text { Distance } \\
(\mathbf{c m})\end{array}$ & $\begin{array}{l}\text { Time } \\
(\mathbf{s e c})\end{array}$ & $\begin{array}{l}\text { Average } \\
\text { Time } \\
(\mathbf{s e c})\end{array}$ & $\begin{array}{l}\text { Speed/ } \\
\text { Diffusion } \\
\mathbf{c m ~ s e c}^{-1}\end{array}$ \\
\hline $\mathbf{P b}^{2+}$ & 29.00 & & 98 & & \\
$1^{\text {st }}$ & 28.50 & 28.30 & 97 & 96.67 & 0.2947 \\
$2^{\text {nd }}$ & 27.40 & & 95 & & \\
$3^{\text {rd }}$ & 30.10 & & 129 & & \\
$\mathbf{B a}^{2+}$ & 29.00 & 29.20 & 127 & 127.33 & 0.2293 \\
$1^{\text {st }}$ & 28.50 & & 126 & & \\
$2^{\text {nd }}$ & 27.90 & & 138 & & \\
$3^{\text {rd }}$ & 29.00 & 28.50 & 140 & 139.33 & 0.2046 \\
$\mathbf{F e}^{2+}$ & 28.60 & & 140 & & \\
$1^{\text {st }}$ & & & & & \\
$2^{\text {nd }}$ & 22.10 & & 140 & & \\
$3^{\text {rd }}$ & 22.40 & 22.27 & 142 & 140.00 & 0.1591 \\
$\mathbf{C a}^{2+}$ & 22.30 & & 138 & & \\
$1^{\text {st }}$ & & & & & \\
$2^{\text {nd }}$ & & & & & \\
$3^{\text {rd }}$ & 20 & & & & \\
\hline \hline
\end{tabular}

Table 2 revealed that diffusion rate of divalent metals is in the order $\mathrm{Pb}^{2+}>\mathrm{Ba}^{2+}>\mathrm{Fe}^{2+}>\mathrm{Ca}^{2+}$. 
Table 3: Comparing Researchers' results with students' results

\begin{tabular}{|c|c|c|c|c|c|c|c|c|c|}
\hline & \multicolumn{3}{|c|}{ Average Distance } & \multicolumn{3}{|c|}{ Average Time } & \multicolumn{3}{|c|}{ Speed $\mathrm{cm}\left(\mathrm{sec}^{-1}\right)$} \\
\hline & $\begin{array}{l}\text { RR } \\
\text { (cm) }\end{array}$ & $\begin{array}{l}\text { SR } \\
(\mathrm{cm})\end{array}$ & DF & $\begin{array}{l}\text { RR } \\
(\mathrm{cm})\end{array}$ & $\begin{array}{l}\text { SR } \\
(\mathrm{cm})\end{array}$ & DF & $\begin{array}{l}\text { RR } \\
\text { (cm) }\end{array}$ & $\begin{array}{l}\text { SR } \\
(\mathrm{cm})\end{array}$ & DF \\
\hline $\mathrm{Pb}^{2+}$ & 27.60 & 28.30 & +0.70 & 93.67 & 96.67 & +3.00 & 0.2949 & 0.2947 & -0.0022 \\
\hline $\mathrm{Ba}^{2+}$ & 29.40 & 29.20 & -0.20 & 126.00 & 127.33 & +1.33 & 0.2333 & 0.2293 & -0.0040 \\
\hline $\mathrm{Fe}^{2+}$ & 28.63 & 28.50 & -0.13 & 139.33 & 139.33 & $0 . .00$ & 0.2055 & 0.2046 & -0.0009 \\
\hline $\mathrm{Ca}^{2+}$ & 22.27 & 22.27 & 0.00 & 139.67 & 140.00 & -0.33 & 0.1594 & 0.1591 & -0.0003 \\
\hline
\end{tabular}

$\mathrm{RR}=$ Researchers' results

RS $=$ Students' results

$\mathrm{DF}=$ Difference between $\mathrm{RR}$ and $\mathrm{RS}$

Table 3 shows that students' results were comparable with the researchers' results. The difference in the researcher's and the students' readings in the above table were insignificant, except for $\mathrm{Pb}^{2+}$. This is because $\mathrm{Pb}^{2+}$ was the heaviest metal and any error in measurement would significantly affect the calculated speed. Thus the students understood diffusion using the new method and material.

To further support the finding of this work, relative atomic masses, ionic radius, speeds of their solvated ions and charge densities were investigated.

Table 4: Relative atomic masses, ionic radii, speeds of their solvated ions and charge densities

\begin{tabular}{lllll}
\hline $\begin{array}{l}\text { Divalent } \\
\text { Metal lons }\end{array}$ & $\begin{array}{l}\text { Atomic Mass } \\
(\mathbf{g} / \mathbf{m l})\end{array}$ & $\begin{array}{l}\text { lonic Radii } \\
\mathbf{X 1 0 ^ { - 9 }}\end{array}$ & $\begin{array}{l}\text { Speeds of } \\
\text { Solvent ions in } \\
\mathbf{C m ~ s e c}^{-1}\end{array}$ & $\begin{array}{l}\text { Charge Densities } \\
\mathbf{X 1 0}^{-18 m}\end{array}$ \\
\hline $\mathrm{Ca}^{2+}$ & 40 & 0.099 & 0.1594 & 64.988 \\
$\mathrm{Fe}^{2+}$ & 56 & 0.074 & 0.2055 & 116.316 \\
$\mathrm{Ba}^{2+}$ & 137 & 0.134 & 0.2333 & 35.472 \\
$\mathrm{~Pb}^{2+}$ & 207 & 0.120 & 0.2940 & 44.232 \\
\hline
\end{tabular}

Atomic mass $(12 \mathrm{C}=12$ scale $)$ ionic radii divided by nanometer.

One nanometer is equal to $10^{-9}$ meter.

Source: Sienko and plane (1976, pp.601-603).

Table 4 is used to plot fig $2 \& 3$. 


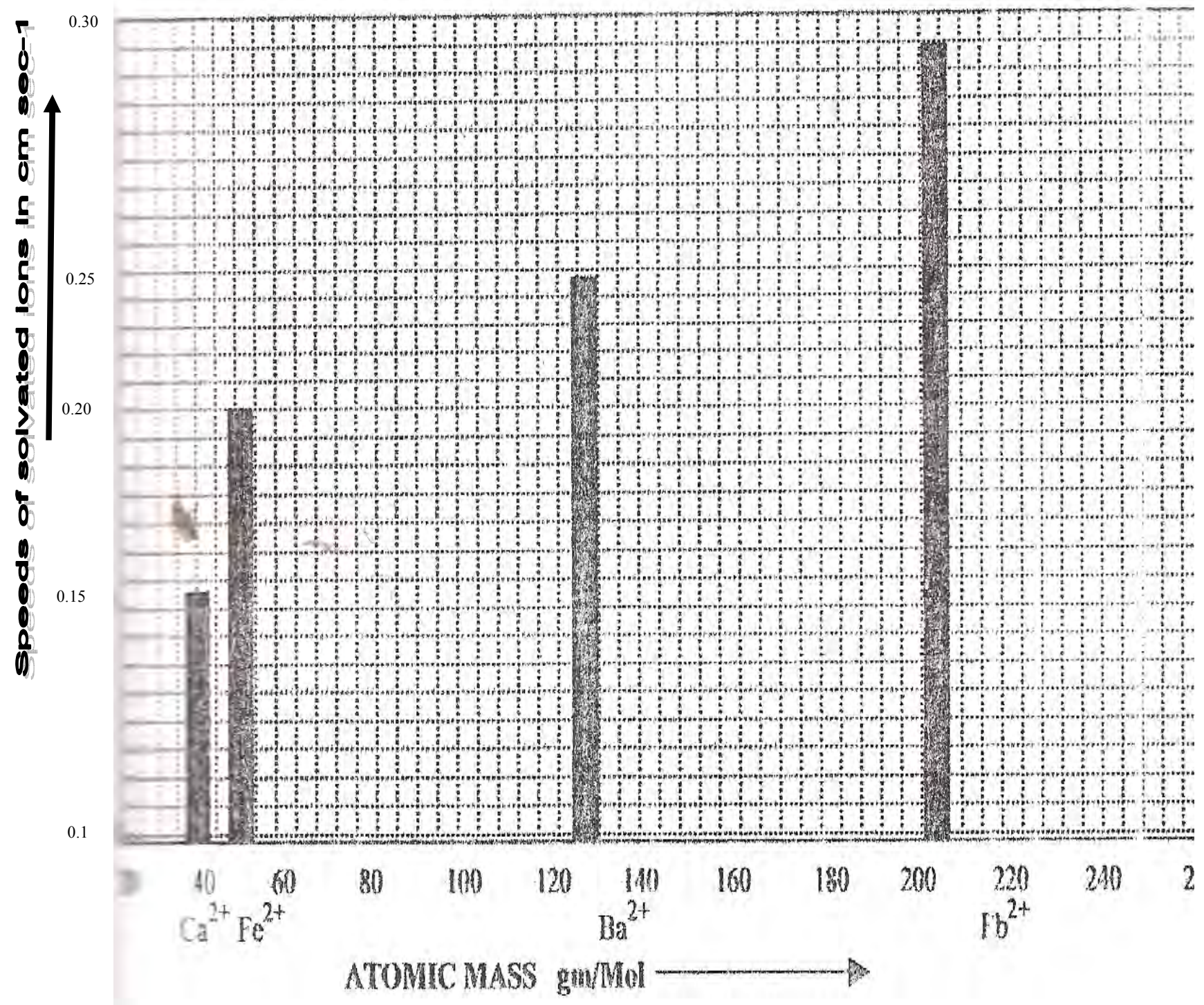

Figure 2: Graph showing a plot of speed of hydrated divalent metal ions against atomic masses This graph shows that the speeds of divalent metal ions are directly proportional to their atomic masses in $\mathrm{g} / \mathrm{mol}$. 


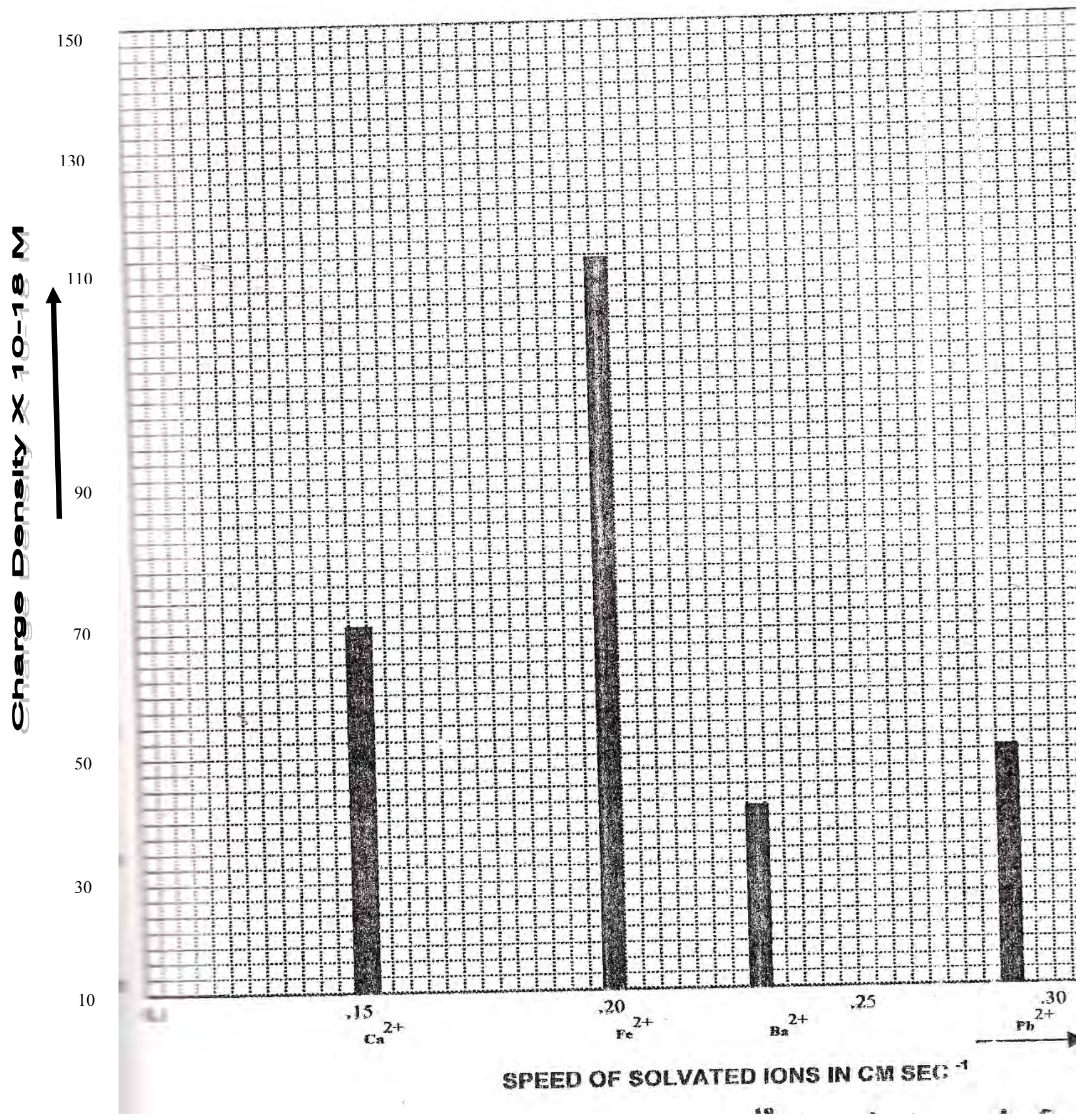

Figure 3: Graph showing charge density $\times 10^{18} \mathrm{M}$ against speed of solvated ions in $\mathrm{cmsec}^{-1}$

Figure 3 show that Iron (II) ion $\left(\mathrm{Fe}^{2+}\right)$ has the highest charge density than all other divalent metal ions under construction. 


\section{DISCUSSION}

An improvised instrument called ionic mobility tube was used to measure the speed of divalent metal ions in aqueous medium.

The addition of the divalent metal salt and Sodium trioxocrabonate $\left(\mathrm{Na}_{2} \mathrm{CO}_{3}\right)$ in an aqueous medium gave a chemical reaction with the formation of a white precipitate or greenish brown precipitate $\mathrm{FeSO}_{4}$. The summaries of the reactions that occurred in aqueous medium are as follows:

$\mathrm{CaCl}_{2(\mathrm{aq})}+\mathrm{Na}_{2} \mathrm{CO}_{3(\mathrm{aq})} \longrightarrow \mathrm{CaCO}_{3(\mathrm{~s})}+2 \mathrm{NaCl}_{2(\mathrm{aq})}$
$\mathrm{FeSO}_{4(\mathrm{aq})}+\mathrm{Na}_{2} \mathrm{CO}_{3(\mathrm{aq})} \longrightarrow \mathrm{FeCO}_{3(\mathrm{~s})}+\mathrm{Na}_{2} \mathrm{SO}_{4(\mathrm{aq})}$
$\mathrm{Ba}\left(\mathrm{NO}_{3}\right)_{2(\mathrm{aq})}+\mathrm{Na}_{2} \mathrm{CO}_{3(\mathrm{aq})} \longrightarrow \mathrm{BaCO}_{3(\mathrm{~s})}+2 \mathrm{NaNO}_{3(\mathrm{aq})}$
$\mathrm{Pb}\left(\mathrm{NO}_{3}\right)_{2(\mathrm{aq})}+\mathrm{Na}_{2} \mathrm{CO}_{3(\mathrm{aq})} \longrightarrow \mathrm{PbCO}_{3(\mathrm{~s})}+2 \mathrm{NaNO}_{3(\mathrm{aq})}$

Laboratory work carried out by the researchers revealed that speeds of divalent metal ions were in the order $\mathrm{Pb}^{2+}>\mathrm{Ba}^{2+}>\mathrm{Fe}^{2+}>\mathrm{Ca}^{2+}$. This is in contrast with the findings of Akins (1979), Brown (1983) and Krestor and Kobenin (1986) who where of the opinion that ions of heavy metals move slower than ions of light metals. The findings of this work is different from normal behaviours of metals where heavy metals move slower than light ones under the influence of the same amount of external force.

When speeds of hydrated divalent metal ions were plotted against atomic masses of the divalent metal ions (Fig. 2), a histogram shows that the speeds of the hydrated divalent metal ions increased as the atomic masses increased, although metals are expected to move in the reverse order where heavy metals like Lead moves slower than Barium and so on.

This observation could be experienced based on the presence of solvent molecules surrounding the central charged atom. Larger atoms have small volumes while smaller atoms have large volumes of the molecules surrounding them. The overall effective masses of hydrated aqueous divalent metal ions are in the order $\mathrm{Ca}^{2+} \cdot \mathrm{aH}_{2} \mathrm{O}>\mathrm{Fe}^{2+} \cdot \mathrm{bH}_{2} \mathrm{O}>\mathrm{Ba}^{2+} \cdot \mathrm{cH}_{2} \mathrm{O}>\mathrm{Pb}^{2+} \cdot \mathrm{dH}_{2} \mathrm{O}$ where $\mathrm{a}, \mathrm{b}, \mathrm{c}$ and $\mathrm{d}$ are the numbers of water molecules surrounding $\mathrm{Ca}^{2+}, \mathrm{Fe}^{2+}, \mathrm{Ba}^{2+}$ and $\mathrm{Pb}^{2+}$ respectively $(a>b>c>d)$ such that the hydrated Calcium ion moves slower than Iron ion, Barium ion and Lead Ion respectively (Gross and Wiseal, 1979).

Table 2 was further used to plot charge densities against speed of solvated ions in $\mathrm{cm} / \mathrm{sec}^{-1}$ as shown in Fig. 3. The graph indicates that Iron ion $\left(\mathrm{Fe}^{2+}\right)$ has a high charge density (116.32) than Calcium ion $\left(\mathrm{Ca}^{2+}\right)$ (64.99), than Lead ion $\left(\mathrm{Pb}^{2+}\right)(44.23)$ and than Barium ion $\left(\mathrm{Ba}^{2+}\right)$ (34.47). If strictly on the basis of charge density, $\mathrm{Fe}^{2+}$ should move slower than all divalent metal ions under consideration. This reverse behaviour of $\mathrm{Fe}^{2+}$ when viewed on the basis of charge density could be explained as resulting from delocalization of the charge on $\mathrm{Fe}^{2+}$ by the influence of empty $3 \mathrm{~d}-$ orbitals. Iron being a transition element has unfilled $3 d-$ orbital which could influence the charge on $\mathrm{Fe}^{2+}$.

The effective charge density could be much less than the calculated, which could lead to the number of $\mathrm{H}_{2} \mathrm{O}$ molecules surrounding $\mathrm{Fe}^{2} \cdot \mathrm{bH}_{2} \mathrm{O}$ to be less than those surrounding $\mathrm{Ca}^{2} \cdot \mathrm{aH}_{2} \mathrm{O}$. This caused the speed of $\mathrm{Fe}^{2+}$ to be faster than that of $\mathrm{Ca}^{2-}$ (Bayim 2005). This hypothesis is subject to further studies.

\section{RECOMMENDATIONS}

Based on the findings of this study the following recommendations were made:

1. Teachers of chemistry in both secondary schools and tertiary institutions should adopt experiments on diffusion using the U-shaped ionic mobility tube as a non-electric field.

2. Curriculum planners should include experiments using ionic mobility tube among recommended experiments in studying diffusion in senior secondary chemistry curriculum.

3. Writers of chemistry textbooks should include experiments in diffusion among the list of experiment for studying solution and mobility of ions.

4. Teachers in secondary schools should teach diffusion as a concept that is real and observable.

5. Teachers in tertiary institutions should include research in diffusion in the list of research studies that could be undertaken by students.

\section{CONCLUSION}

The outcome of this research work shows that experiment involving measuring of speed of ions in aqueous medium can also be conducted in the absence of an electric field. 
This compares favourably with that conducted in an electric field.

An improvised $U$ - shaped tube called ionic mobility tube is an effective apparatus used in conducting experiment and studying diffusion of ions in aqueous medium.

The study also reveals that ionic mobility tube is an effective instrument used to measure charge densities of ions, their speed as well as distances of ions in aqueous medium.

\section{REFERENCES}

Atkins, P. W., 1979. Physical Chemistry. Oxford: Oxford University Press Walton Street.

Bayim, B. A., 2005. The mobility of Divalent Metal lons in a Non-electric Field and its Application in the Teaching and Learning of Ionic Mobility in Aqueous Medium. Unpublished Masters Thesis Uniuyo Uyo.
Brown, G. I., 1983. Introduction to Physical Chemistry. (S.I. ed.) Liverpool: Longman Group of Coys Ltd.

Eshiet, I. T., 1988. The Use of Deductive Inquiry Approach in the Experimental Study of the Concept of Solution of lons. Journal of Science Teachers Association of Nigeria, 26 (1). $21-28$

Gross, J. M. and Wiseal, B., 1979. Principles of Physical Chemistry. Suffock: MacDonald and Evans Ltd.

Krestor, G. A. and Kobenin, V. A., 1986. From Crystal to Solution. Moscow: Mir Publisher.

Sienko M. J. and Plane, R. A., 1981. Chemistry. (Fifth Edition) London: McGraw - Hill International Book Coy. 